\title{
"Red is not the only color of a rainbow": The making and resistance of the "MSM" subject among gay men in China
}

\author{
Chuncheng Liu \\ Department of Sociology, University of California San Diego \\ Email address: chchliu@ucsd.edu
}

Forthcoming: Social Science \& Medicine

\begin{abstract}
Public health scholars classify gay men as "men who have sex with men (MSM)" in their studies and interventions. Debates have been raised about the MSM classification for decades. However, we know little about how people who are classified as MSM perceive and respond to this classification, particularly in the authoritarian context where the biopower interacts with the repressive state power. Drawing upon Ian Hacking's dynamic nominalism theory, this study tries to fill these gaps with interviews of 40 gay men in three Chinese cities about their interactions with public health education materials. I examined their perceptions of MSM knowledge and discourses associated with the classification, as well as their identifications to the MSM subject. I found that, on the one hand, many gay men had internalized the MSM subjectivity and considered themselves essentially at high risk of HIV infection. This compliance was constructed through various biopower techniques with the support of the state's repressive power, as the Chinese state censored almost all public representations of gay men except the HIV/AIDS subject MSM. On the other hand, some of my interviewees were resistant to be part of the MSM classification. I showed how this failure is an unintended consequence of the hegemonic MSM discourse and the authoritarian regime's institutional exclusion of the gay men's community's engagement in the expertise network that develops intervention materials and strategies. At last, I proposed to move beyond the debate around the name and representational character of the MSM by moving toward a more reflexive public health.
\end{abstract}

Keywords: men who have sex with men (MSM), public health, HIV/AIDS, dynamic nominalism, biopolitics, authoritarianism, China 


\section{Introduction}

Since the beginning of the AIDS epidemic in the 1980s, public health has played an increasingly critical role in producing scientific facts about gay men, and it has reshaped their community globally. Gay men's community is one of the places where the AIDS epidemic broke out, and since then, has disproportionately contributed to newly diagnosed HIV cases (Beyrer et al., 2012; Epstein, 1996). Over decades, epidemic surveillance systems and other public health institutions came into being in gay men's community. Public health research regularly produces knowledge about gay men and interventions aimed at them that circulate through policies and the mass media. In other words, gay men have become a subject of public health's gaze (Foucault, 1990; Kong, 2016; Lupton, 1995).

This gaze institutionalizes the classification "men who have sex with men (MSM)" as one of the "high-risk populations of HIV/AIDS" from the public health perspective. Presently, most public health research, policies, and interventions regarding gay men are conducted under the rubric of "MSM" (Beyrer et al., 2012; Young and Meyer, 2005). With the expansion of global health programs worldwide, the classification and the term "MSM" have been used in almost all societies with global health projects, from Asian to African (Asthana and Oostvogels, 2001; Boellstorff, 2011). Although MSM looks like a pure behavior-based, ahistorical and universal concept, the current use and meaning of MSM were deliberately invented and crystallized in a public-health-institutions-centered "network" (Eyal, 2013; Latour, 2005) for specific purposes in the HIV/AIDS epidemic context.

Public health institutions do not only create the MSM classification to study people who are under it. They also actively try to make people under this classification to understand and internalize their status as MSM, i.e., the high-risk population of HIV/AIDS (Lupton, 1995). Through these practices could people be involved in the public health network, understand their risks, and behave in a safer way. However, people who are MSM in practice do not necessarily know and identify themselves as the public health subject "MSM." Public health professions need to develop various interventions. They routinely mobilize different entities, such as the international organizations, state apparatuses, media, LGBTQ non-governmental organizations (NGOs), and even lay gay men themselves into the expertise network (Guta et al., 2014; Liu and Meyers, 2019). Non-human agents such as intervention materials, international guidelines, 
surveillance reports, journal articles, news reports, state policies are also part of the network to expand, establish, and stabilize the associations.

Health education materials are one of the most important products of this expertise network and the intermediary agents that fill the gap between public health knowledge and its target populations (Liu, 2010; Lupton, 1995). The distribution of health education material, such as posters on the street, columns in newspapers, posts on social media, are common forms of HIV/AIDS public health intervention. An education material is usually a combination of text and image that raises risk awareness (e.g., MSM is a high-risk population), promotes knowledge (e.g., the transmission routes of HIV) and encourages specific health behaviors (e.g., condom use or HIV testing) (Liu, 2010; Zhang, 2017).

This study examines the making, sustaining, and resistance of the abnormally strong association between public health classification MSM and its most important target population, gay men, in China. Scholars have noticed that public discourses and academic research about gay men in China are dominated by public health, more specifically, HIV/AIDS concerns (Huang, 2018; Kong, 2016; Sun, 2016). A recent study shows that Chinese gay men experience a significantly higher level of fear toward HIV/AIDS issues and stigma toward themselves compared with their counterparts in other countries, such as the United States and Thailand (Liu et al., 2020). However, gay men were not initially heavily affected by the Chinese AIDS epidemic, and they still, in 2016, contributed to $27.6 \%$ of the newly-diagnosed HIV cases (China Centers for Disease Control and Prevention, 2017). In many developed western counties, this proportion was often much higher, such as 68\% in the United States (United States Centers for Disease Control and Prevention, 2017) and 62\% in Australia (Australian Federation of AIDS Organizations, 2020).

To answer this puzzle, I examine how Chinese gay men perceive their relationship with the public health's conceptualization of them through public health education materials. I ask two interrelated questions: First, how do public health research and interventions instantiate MSM knowledge and discourse toward gay men through health education materials? Second, how do gay men perceive and respond to MSM knowledge and discourse that appear in public health education materials?

Previous studies on the MSM classification mostly focus on its representational issues and linguistic politics of its name. Yet this study aims to explore the process of making and resistance 
of the MSM as a public health subject, which will advance our understandings about how institutions, discourses, and materials could be mobilized to "make up of people" (Hacking, 1996, 2007) and construct symbolic violence in the interaction between knowledge and power. Specifically, this study will show how the reproductive biopower could collaborate or contradict with the repressive power of the authoritarian state in making subjects, and how a reflexive public health perspective, i.e. an active engagement in the complexity of categorization and knowledge production (Perez-Brumer et al., 2016), are needed.

I will firstly discuss politics around the literal use of "MSM" among gay men. I find most gay men do not perceive it as a problematic name to refer to themselves, which may be a surprise to many scholars who speculate of the misrepresentation problems of the "MSM." Instead, I argue that MSM is more than a name, but a subject that carries specific knowledge and assumptions about itself. I then illustrate how public health institutions produce the MSM subject in education materials and mobilize social actants through various biopower techniques to establish gay men's internalization of the MSM subject. Particularly, I show how the authoritarian state repressive practices, such as censorship, could facilitate the transformation of gay men into the compliant MSM subject. Lastly, I present an unintended consequence of the seemingly invincible combination of public health biopower and state repressive power. I show how the latter ironically highlights the gap between gay men's identity and the MSM subject and thus becomes a barrier to the biopower's operations.

\section{MSM as a representation}

The term "men who have sex with men" first appeared in a public health article in 1988, oddly enough, discussing women's HIV risk (Mantell et al., 1988). It became commonly used and institutionalized in public health in the early 2000s (Boellstorff, 2011). Epidemiologists created this behavior-based category as an analytical tool distinct from identity-based categories like gay and bisexual for two main reasons. First, it could cover those men who have sex with men "but do not identify as gay," a group that is also considered the "high-risk population of HIV/AIDS." (Boellstorff, 2011; Young and Meyer, 2005) Second, it intends to detach the stigmatized 
HIV/AIDS label from sexual identity (Muòoz-Laboy, 2004; Perez-Brumer et al., 2016; Young and Meyer, 2005).

While the MSM classification certainly has many merits, social science and humanities scholars have pointed out its varied shortcomings, particularly its misrepresentation and mismatch between the classification and the people it classifies. First, its emphasis merely on the behavioral aspect of the population leads to a dismissal of the rich cultural, social, historical, and even erotic dimensions of human sexuality (Adam, 2011; Muòoz-Laboy, 2004; Perez-Brumer et al., 2016; Young and Meyer, 2005). Second, MSM contains a diverse group of people with different social characters, which are often ignored by grouping them into one homogeneous classification (Truong et al., 2016; Young and Meyer, 2005). Lastly, the original distinction between MSM and gay is largely ignored in actual use, which invalidates the classification from its beginning (Boellstorff, 2011; Carrillo and Hoffman, 2016; Martucci, 2010).

With the aid of global health programs, MSM travels from Western society to the rest of the world. Meanwhile, the "misrepresentation and mismatch" critiques of MSM cross-fertilize another rich literature: the discussion of the use of Western-origin classifications in non-Western contexts. For example, scholars show that the use of MSM shadows the local cultural kothis/panthis subjects that are commonly used in India (Asthana and Oostvogels, 2001; Boyce, 2007), particularly in global health standardization surveys and interventions (Lorway, 2017). These criticisms of the misrepresentation that MSM carries are insightful. Yet most of them often assume that people who are classified are the passive receivers of the classification, and MSM's ahistorical and decontextualized character is problematic universally. They ignore that the classification is constantly remade by the people who are classified with the new meanings they created (Eyal, 2013; Hacking, 2004, 1996).

Meanwhile, studies of gay men's perception of public health intervention materials are mostly concentrated in the field of implementation science, where scholars focus on the technical and instrumental dimensions of intervention materials with the goal of improving their quality. For example, implementation scientists evaluate, in different settings, the quality of health education materials for clarity, humor, and knowledge accuracy (Ballester-Arnal et al., 2015; Bastien, 2011). However, these studies largely ignore the potential gap between the MSM name/subject and the gay audience. Also, these studies often assume the problem is the result of individual or 
organizational incapacities in producing "good" materials, neither considering how education material productions are embedded in a broader sociopolitical environment nor rethinking the production of knowledge and interventions.

In short, scholars have criticized the term "MSM" as a representation in the static, universal, and conceptual level or its literal use. Yet the empirical findings of the "politics of knowledge" that are commonly observed in the HIV/AIDS field (Epstein, 1996) are largely absent in studies of the MSM classification.

\section{MSM as a subject}

Ian Hacking's theory of dynamic nominalism $(2007,2004,1996)$ could shed critical insights into the MSM classification. As the name implies, dynamic nominalism is a "nominalism in action" (Hacking, 2004, p. 278). It points out that the relationship between the classification and people it classifies is not a one-way and determined, but rather mutual and interactive. This performative perspective of the politics around a name helps us to focus on the interventional aspect of a classification, instead of merely discussing issues of representation. Borrowing from Barad's (2007, p.133) words, it could "shift the focus from the question of correspondence between descriptions and reality to matters of practices/doings/actions." Meanwhile, classifying people often results in a "looping effect" (Hacking, 1996). This means that the new classifications often alter the way classified people think, behave, and live, which further reshapes the classification itself.

Under this perspective, MSM is not merely a term, a name, or a representation of a group of people that are already "there" before the classification is invented. Instead, it makes up new "kinds of people" that opens new possibilities and realities in people's lives who are grouped under this classification (Hacking, 2007). Similar to Hacking's (1996) analysis of the invention of "multiple personality disorder" and Foucault's (1990) analysis of the invention of "homosexuality" in the late 1800 s, there have always been men who have sex with men. However, categorizing these people into one group with the abbreviated name "MSM" under public health's gaze is a new practice. The MSM classification creates a new subject and a new way of thinking based on public health knowledge and discourses that highlights the "high-risk of HIV/AIDS." 
The association between gay men and HIV/AIDS through MSM, however, is not self-evident. The establishment and stabilization of such association also are not spontaneous or merely determined by the "fact" that MSM has a higher proportion of HIV infection compared with the general population. Science studies scholars have shown that even for the most obvious "claim of truth," scientists need to mobilize various social actors and adopt strategic techniques to enable it to achieve the taken-for-granted status (Eyal, 2013; Hacking, 2007; Latour, 1987). As Hacking (2007, p.292) stresses, this process involves institutions, knowledge, and experts that "generate or legitimate knowledge, judge its validity and use it in their practices." A gay man's realization and adoption of the MSM subjectivity is a result of such efforts.

Previous studies on biopower mechanisms in the interaction between public health knowledge and gay men primarily focus on cases in Western democratic contexts. For example, Guta et al. (2014) examined how community-based research has been utilized as a governmentality tool for surveillance and control of the gay men's community by researchers in Canada. Yet we know little about how reproductive biopower may intertwine with repressive sovereign power in constructing and shaping the sexual and medical subject. Research in an authoritarian regime like China could offer us valuable insights that could not be easily observed elsewhere to fill this gap in the current literature. As Lieberthal and Oksenberg (1990) noted, China's authoritarianism is not a monolithic repressive entity but fragmented: Different governmental agencies across localities may have their own interests and logics when practicing power, and different kinds of power practice constantly interact with each other. We can observe a spectrum of dominated power forms across Chinese governmental agencies.

In summary, neither the process of making the MSM subject and nor the gay men's response to this subjectification is spontaneous. Instead, they are both enabled or challenged by active interactions and mobilizations of various social actors and techniques, which I will examine in the context of interactions between China's repressive sovereign power and reproductive biopower. The former power is mainly practiced by governmental agencies (e.g. police department) while the latter is practiced by both governmental agencies (e.g. Centers for Disease Control and Prevention, CDC) and non-governmental parties (e.g. LGBTQ NGOs). 


\section{Methods}

From May 2017 to June 2019, I interviewed 40 gay-identified men through five semi-structural focus groups (21 men) and 19 one-on-one interviews in three different Chinese cities: Beijing, Changsha, and Guangzhou. All these three cities had active gay men's communities and long-term HIV/AIDS campaigns targeting at MSM. I selected these cities based on geographic, socioeconomic, and civil society development diversities (Table 1). Their diverse characteristics gave us a more comprehensive understanding of the politics around MSM in China. I recruited the interviewees through an LGBTQ NGO in Guangzhou and social media platforms of a multi-site public health program in Beijing and Changsha. All interviewees had sexual experiences with men in the past, thus met the classification standard of "men who have sex with men." Their ages ranged from 21 to 54, with an average age of 27.4. They came from diverse backgrounds, from NGO staff to blue-collar workers. The focus group interview guide was not directly designed for this study but aimed to evaluate interviewees' general experiences, perception and preferences about HIV/AIDS-related education materials for another project. Questions from general impressions such as "where and when do you see the public health education material, what do you think of them?" to specific symbol use, such as “do you like this poster's use of the national leader's picture? Why or why not?" were asked with the presentation of commonly used public health posters. Oneon-one interviews were designed for this study focally, although no specific education materials were shown during interviews.

Table 1. Comparison between Beijing, Changsha, and Guangzhou

\begin{tabular}{llll}
\hline & Beijing & Changsha & Guangzhou \\
\hline Location & North China & Middle China & South China \\
& Developed but with & Less developed and & Developed and fewer \\
Civil society & strong restraints by & fewer restraints by & restraints by local \\
& local government & local government & government \\
GDP (billion RMB) & $2,800.04$ & $1,053.55$ & $2,150.32$ \\
Population (million) & 21.71 million & 7.92 million & 14.50 million \\
\hline
\end{tabular}

Note: GDP and population data from China Statistical Yearbook 2017 (National Bureau of Statistics of China, 2017) 
This study limited participants as gay-identified men for three reasons. First, the purpose of this study was to examine the interaction between public health materials and one's sexual identity in (de)stabilizing the MSM subject. I intended to control the variations between different sexual orientations to focus on this process itself. Second, it was more typical to select gay men as my study participants, as they predominately occupied the MSM classification in public health's research and interventions. Third, this study started from a focus group, which was designed for gay men only. For the sake of consistency, this study continued to focus on gay men.

Both focus groups and one-on-one interviews were conducted in Mandarin Chinese and lasted from 40 to 120 minutes. Interviewees gave their consent to be recorded, and I transcribed the interviews word-by-word and analyzed them in NVivo 11. I anonymized all personal information to protect privacy. Besides my interview data, I also included typical public health education materials and conducted context analysis on them to better contextualize and illustrate the qualitative findings.

Overall, I adopt the abductive analysis strategy (Timmermans and Tavory, 2012) for this study. I initiated the study with the familiarity of Foucauldian biopower and cultural-linguistic identity theories. With the progress of the study and constantly revisited of my data, I realized the limitations of these theoretical frameworks in explaining my data and started to incorporate fragmented authoritarianism and Hacking's dynamic nominalism. Latour's actor-network theory (ANT) also inspired my analytical focus, which emphasized the process of how various human and non-human actants could be mobilized to stabilize associations into facts. Instead of simplifying rich qualitative interviews into codes, I used thematic analysis methods. I familiarized with the data first and developed an initial thematic structure, then I highlighted key elements in different themes, went back forth between the thematic structure and interviews, and formalized the final thematic structure. The study obtained ethical approvals from the ethics review committees at Guangdong Provincial Centre for Skin Diseases and STI Control, University of North Carolina, Chapel Hill, and Fudan University. 


\section{"It's not about the name": the insignificant politics of the name "MSM"}

I feel, this labeling could cause many stereotypes, which would have very bad consequences to the community [...] Sometimes we attach too many additional meanings to a label, and, people are judgmental... (Lin-Lin, college student in public health, Changsha)

Lin-Lin, a public health major college student who well understood the rationale of the MSM classification was against its use to describe himself and his community. His critiques of the term "MSM" allied with previous scholars" worries about labeling and stigmatization effect that "MSM" as a name might imply (Truong et al., 2016; Young and Meyer, 2005). However, such critique of the use of "MSM" was rare in my interviews. In addition, unlike what many scholars who opposed the use of the Western-originated, ahistorical, and decontextualized category MSM to describe people in non-Western societies may expect, many of my interviewees preferred to use the term "MSM" in English or Chinese ("nannan") to describe themselves. Da-Wang, an HIV/AIDS service NGO worker said:

Men who have sex with men (nannan xingxingwei renqun), man and man (nannan), right? MSM, gay, tongzhi... The specific terms are different. But overall, they are all the same: homosexual (tongxinglian) [...] But MSM is way better than homosexuals, I hate when people call me "homosexual," their tones always mixed with discriminations... You can say "MSM" or "nannan" very casually in the public without being noticed — only those people who knew would understand. (Da-Wang, NGO worker, Beijing)

Da-Wang's comments were more common among my interviewees. Similar to findings from other socio-cultural contexts (Asthana and Oostvogels, 2001; Boellstorff, 2011; Carrillo and Hoffman, 2016), MSM was commonly used as a euphemism for "homosexual" by many gay men I interviewed. Based on the literal characters of the term "MSM" and without understanding its original meaning or goal, gay men created new meanings for "MSM" that were different from public health's conceptualization.

This kind of linguistic politics had been observed among the Chinese gay men's community. As Da-Wang indicated, "tongxinglian," the Chinese name of "homosexual," was largely 
considered as a negative and awkward name for Chinese gay men's identity. Gay men reappropriated other terms (such as "tongzhi," which means "comrade") or used other languages (such as "gay" in English) as euphemism to avoid the stigmatized meanings associated with "tongxinglian" (for more detailed discussions of these linguistic politics, see Rofel, 2007 and Wong, 2005). Yet when "gay" and "tongzhi" were too well known to avoid homosexual-related stigma, using "MSM" as a euphemism for these terms allowed some gay men to communicate with each other without being exposed. The ahistorical and decontextualized characteristics that scholars criticized were, in fact, advantages in the less tolerant Chinese social context.

However, even though Da-Wang's views were shared by more people I interviewed than LinLin's, people who had any attitude toward the name "MSM" only occupied a small part of my study; and they all studied or worked with public health institutions. Most of the gay men I interviewed never used "MSM" to describe themselves, noticed much about it, or problematized "MSM" as a term at all. At the end of my interview with Xiao-Bei, a medical researcher who was quite familiar with public health research through his engagement in local NGO, said to me: "I don't understand why you care about the name. It's not about the name, the problem we have is more than the name."

As Hacking (2007, p. 295) put, "name is only part of the dynamic.” My following sections will show issues of "MSM" not as a name of classification, but as a subject of public health. The MSM subject epitomized the association between gay men and HIV/AIDS through mobilizations and institutionalizations of public health knowledge and discourse. Regardless of whether a gay man knew the name "MSM" or not, he was the MSM subject under the gaze and influence of public health. Regardless of whether a gay man compliantly internalized this MSM subject or actively resisted it, he was not indifferent to it and he cannot ignore it.

\section{"I am at high risk": The making of the compliant MSM subject}

How would a gay man realize and internalize his connection with HIV/AIDS? During the general discussion regarding what people learned from health education materials, Xiao-Yang, a factory worker recalled the poster he saw near his dorm and said: 
I think gay men are more easily infected with HIV ... but now think about it, I never really think about why because... you know, there are news and CDC statistics reports every year. The numbers are on the poster. Numbers do not lie. [...] It's like common sense already. (Xiao-Yang, factory worker, Guangzhou)

Xiao-Yang's trust toward "numbers" was common among the interviewees, which showed how powerful numbers could be in constructing social classification (Hacking, 2007; Waidzunas, 2012). Numbers regarding HIV/AIDS and MSM were often displayed in education materials in the form of an absolute figure, such as "900 MSM college students were infected with HIV in the last year," or a percentage, such as "You don't know how close HIV/AIDS is to us! Every $\mathbf{1}$ in $\mathbf{1 0}$ MSM population around you is living with HIV." (Figure 1) These numbers were often presented in a self-evident and conclusive way, while the specific context of the number was commonly ignored. Taking a CDC poster (Figure 1) for example, while the number (1 in 10 MSM is living with HIV) might be true in a specific case, no context of where this number came from was offered in the poster. It was almost as if the "1 in 10" was a universal and essential truth about MSM. Yet science studies had told us that numbers are not truth by themselves. They are, instead, always situational to achieve specific goals (Lampland, 2010).

\section{Figure 1. HIV/AIDS intervention poster from Yinzhou CDC, 2018}

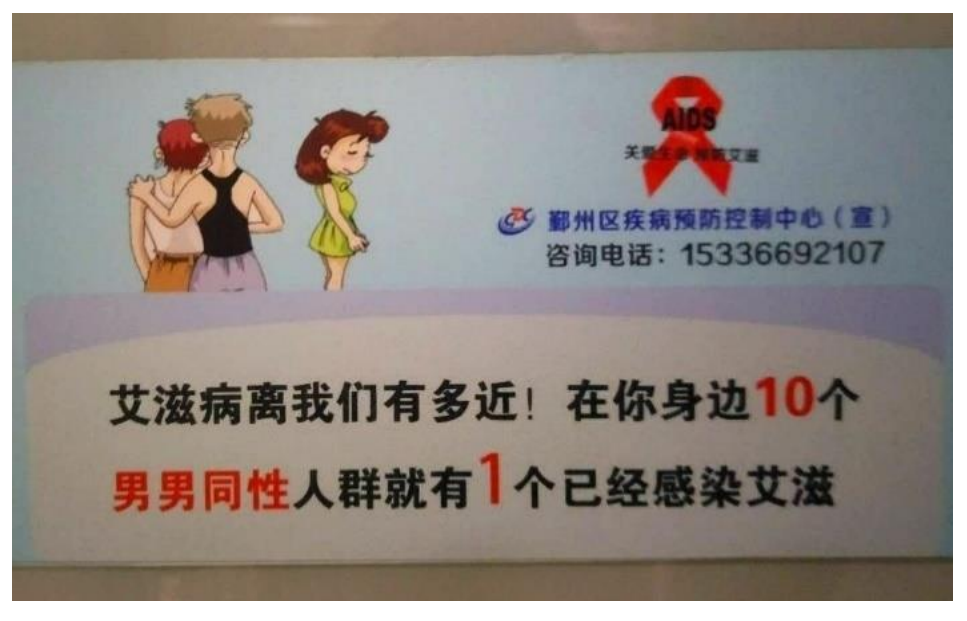

Note: "You don't know how close HIV/AIDS is to us! Every $\mathbf{1}$ in $\mathbf{1 0}$ MSM population around you is living with HIV" 
In addition, this poster, like many other public health education materials in China, intentionally or unintentionally blurred the difference between population prevalence and individual risk. This practice resulted in the essentialization of population-level correlations into individual identities, as an individual gay man often seemed to be at risk solely because of his identity or behavior. As one interviewee recalled: "they (the education material he knew) only say that gay men are a high-risk population, while I am a gay man, I would think... I am at high risk." (Hai-Zi, nurse, Beijing)

Furthermore, what Hacking (2007) described as "biologization" also applied to the making of the compliant MSM subject. Public health knowledge considered the biological characteristics of sexual behaviors among men as important evidence of MSM as the high-risk population for HIV/AIDS. A common theory was that the anal mucosa was thinner than the vaginal mucosa, and thus it put MSM at a higher risk of HIV transmission. Yet, this seemingly self-evident and naturalized explanation was problematic as it ignored the nonbiological characteristics during sexual behaviors. When discussing with a focus group in Guangzhou on why health education materials portray gay men as the highest risk population for HIV/AIDS, a conversation happened:

Da-Li (office worker): I think it is about anal sex, right? Because the tissue there is thinner, so it is easier to bleed compared with heterosexual vaginal sex.

Lu-Lu (graduate student in communication): But can’t a condom protect you?

Da-Li: Yeah. I think so... Hmm... Now it's strange to me.

The decontextualized numbers, the blurring of population/individual risk boundaries, and biological discourses were all part of the biopower techniques that public health institutions utilized. They powerfully facilitated the internalization of the MSM subjectivity to gay men and put them into the MSM loop when they were exposed to public health education materials. Even for some gay men who had never had sex with men, by definition not within the MSM classification, the common discourse regarding the dangerous association of his sexuality and HIV/AIDS resulted in the stigmatization of same-sex behaviors in a strange way. For example, Lu-Lu shared question he saw on an online platform: 
There were people asking, if both of them do not have HIV, would condomless anal sex have HIV infection risks? I know this sounds ridiculous, but when I saw that post, I was thinking maybe the promotion (of HIV/AIDS risk among MSM) went a little bit too far. (Lu-Lu, graduate student in communication, Guangzhou)

This knowledge and discourse of MSM not only influenced gay men, but also people who were around them. These people perceived and internalized the association between gay men and HIV/AIDS through various channels and then became parts of the network of this association. By incorporating people around gay men, the "universal" knowledge and claims became more localized and effective (Latour, 2005, p. 178), which reinforced the establishment of the MSM subject. Xiao-Zhe, a 21-year-old college student complained:

You know what? Every year when AIDS-related reports come out around World AIDS Day, my classmates send me information regarding it. I'm publicly out, you know. So, they would say, "wow look at you, homos!" (Xiao-Zhe, college student in computer science, Guangzhou)

More importantly, public health institutions' biopower practices were largely supported, directly or indirectly, by China's authoritarian repressive state power practices. The Chinese government agency on media had strict regulations regarding LGBTQ related content while the government agency on civil affairs had strict regulations on LGBTQ NGO activities. For example, domestic LGBTQ issues were discussed largely only as an HIV/AIDS subject in the official media (Huang, 2018). Restraint toward and censorship of other aspects of LGBTQ related issues have been particularly reinforced in recent years with the general regression of the Chinese civil society. For example, a new media regulation by the Chinese National Radio and Television Administration in 2017 forbid the appearance of sexual minorities in movies to avoid promoting "wrong and immoral values." Although this rule had been loosely guiding the censorship of media representation unpublically for decades, the explicit ban was new, indicating a different level of regulation. Most of the TV shows that had LGBTQ characters, a small number in total, were removed or banned after the rule was published. Long-Long, a young state-owned enterprise office worker resentfully said:

I have not seen any other kinds of public discussion regarding gays. All the TV shows about gays were banned by the government earlier, and I remembered that one 
university student tried to sue the Ministry of Education for allowing antihomosexuality textbook distribution among students [...] but did you hear anything about that? No, it was all removed from social media. (Long-Long, office worker, Guangzhou)

Although gay men's NGOs were the most successful kind of LGBTQ NGOs in China in terms of number, visibility, and resources, their non-HIV/AIDS-related activities were often strictly restrained by different government agencies (Chua and Hildebrandt, 2013; Long, 2018). Sometimes, public health authorities would also cooperate with other government agencies to repress NGOs and use the control of their funding to ensure their obedience (Liu and Meyers, 2019; Miller, 2016). For example, Dan-Dan, a Changsha gay men's NGO leader said that they cannot even promote their monthly book club activity on their social media platform now:

Everything is sensitive now, except taking others' blood (and run HIV testing). Our book club was fine for a long time until suddenly some officials told us it is not OK to say it on our social media platforms. [...] all the civil society stuff became sensitive after 2017, not only the LGBTQ field, and we do understand the difficulties of our supervision governmental agencies. They have their higher authorities supervising them too. If you think like a governmental official, you may worry: what if people start to discuss some politically sensitive issues? What if people want to have same-sex marriage?

By eliminating other contested symbols, MSM, the HIV/AIDS subject, was almost the only representation of gay men that was publicly available, through which reconfirmations of the association between HIV/AIDS and gay men were constantly made. Medicalized and HIV/AIDSrelated concerns thus achieved hegemonic status and dominated the current public discourse regarding gay men in China. This classification's looping effects thus had a significant influence in shaping the subjectivity of gay men. Instead of empowerment, the "significance" of "gay men's" representation in society became a curse and produced a stigma toward their community. Lao-Shi, a 54-year-old factory owner and local NGO volunteer in Beijing articulated this point:

There are many people have homophobia, one of the biggest reasons is that they think gay men are associated with HIV. [...] Sometimes I think our organization's existence may actually reinforce this image. Are we a HIV organization, or a gay men's organization, or, as you asked, an MSM organization? I don't think outsiders could 
really tell the differences. Let me be honest with you, if it is not you keep asking me now, I don't think I clearly know the differences too.

\section{"Not gay enough": The resistance to the MSM subject}

As Foucault (1990, p. 95) famously put it: "Where there is power, there is resistance." Gay men did not simply accept and internalize the MSM subjectivity. Unintended consequences did happen from time to time, break the looping effect, and destabilize the public health's network of the MSM subject. Some gay men, even those who were in favor of using the name "MSM" to describe themselves, felt skeptical, reluctant, or even actively resist MSM discourse and subjectivity that associated themselves with HIV/AIDS. Some of them were explicitly against the essentialization of the risk status in the MSM classification and challenged it in a more radical way by claiming that: "There is no high-risk population, but only high-risk behaviors."

Many of my interviewees identified the gap between their identity and the MSM subject. In fact, this gap was highlighted in the health education material itself. People frequently complained about the poor design of those education materials. When I asked participants' general impressions regarding public health education materials, a common response was that "they were not gay enough," following by comments of how they were "boring" in form, "dry" in content, or "ugly" in design and thus cannot draw people's attention or make people feel related. Fei-Fei, a graduate student from the Guangzhou focus group recalled:

I saw many posters and manuals that CDC printed on the campus every year around World AIDS Day. However, they are all very dry: just too much text and too much content! I don't feel that it is related to me, although they sometimes say quite explicitly that gay is a high-risk population along with drug users and other people...

In addition, many interviewees reported that the strategy underlying many education materials was problematic. A-Luo, a "normal salaryman" in his own words, recalled his experiences in coming upon HIV-related posters in Guangzhou:

I think the way they promote this is not very appropriate. There are too many warnings, intimidating stuff in those posters and articles. I don't even want to look at them, it's 
terrifying. It's been years... I think it wants to frighten people from HIV/AIDS. But what it does is it just makes people not want to think about it or just think it's too far away from themselves, so keep doing whatever they are doing now. (A-Luo, office worker, Guangzhou)

Those "warnings" and "intimidating stuff" on the education materials were guided by a public health strategy called "scare tactics." The scare tactics assumed that by constructing a terrifying image of the disease, people will be "scared" and less likely to conduct high-risk behaviors to avoid their destructive consequences. Figure 2 is an example of a poster that adopts such tactic. Although my interviews and many studies had shown that scare tactics serve as a significant barrier to acquiring HIV-related healthcare services, because for most of the time, fear discouraged healthcare-seeking (Altman et al., 2012; Bastien, 2011), such tactics was still very common in HIV/AIDS interventions in China (Liu, 2010; Zhang, 2017).

\section{Figure 2. "Special column on AIDS prevention" poster utilizing scare tactics}

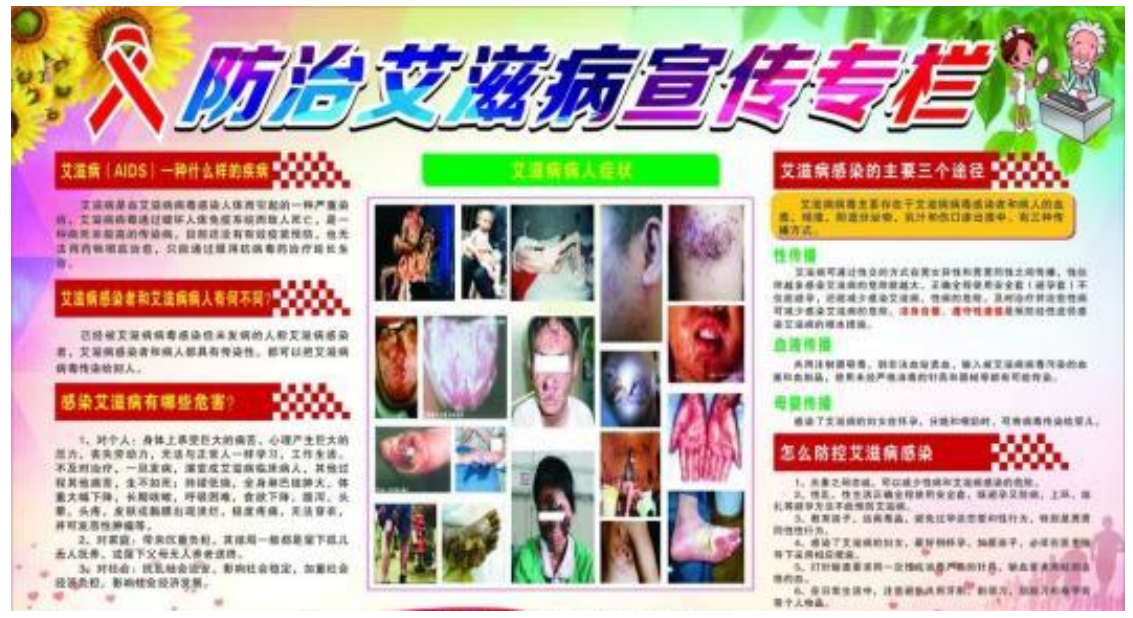

Note: 1) the third section in the left, "what is the danger of getting HIV," indicates that for the individual there will be: physical and psychological pain, "living hell," lost weight, headache, skin problems, cancer, and death; 2) for the family: the family will be broken, children will become orphans, parents will die alone; and 3) for society: destabilize the society and become a burden to the society. The middle section is called "the symptoms of AIDS patients." 
Image sources: http://www.photophoto.cn/pic/23095540.html This is a very representative HIV/AIDS education material that utilized scare tactics, and many contents of this poster have been seen in other CDC published materials, such as an article on Kunshan CDC's website's "health education topic" (http://www.kscdc.com/contents/1083/9208.html). Yet no evidence showed how this specific poster was used in any specific venue before.

The multiple ways in which health education material lacked "gayness" signified the gap between the medicalized subject of risk, MSM, and its target, gay men. The failure of associating the former with the latter, however, was not an isolated problem of one local public health authority, as I found similar complaints from interviewees across China. Instead, the problem could at least be traced back to the paradigm of public health itself. Long-lasting behaviorism and individualism in the public health paradigm influenced public health interventions (Lupton, 1995; Perez-Brumer et al., 2016). As a study in India showed, public health professionals were more likely to focus on short-term behavior changes in the intervention design and leave hard-to-address cultural and identity contents out (Asthana and Oostvogels, 2001).

Ironically, the repressive state power that aimed to reduce the civil and cultural experiences of gay men into the medicalized MSM also contributed to this gap between MSM and gay men. Unlike its counterparts in the United States and other Western societies (Epstein, 1996), the Chinese gay men's community had not gained comparable credibility and power in the Chinese HIV/AIDS epistemic community for policymaking or intervention decision-making. Even though Chinese public health authority may be the most open government agency in China - in its willingness to cooperate with community stakeholders - their cooperation was often in the form of "order-response," instead of an equal partnership (Liu and Meyers, 2019; Long, 2018). For example, Yan-Zi, a Guangzhou NGO leader confessed to me:

We are supposed to represent the community's voice, but most of the time it is more like we are doing works for the government or the hospital, simply because they cannot reach out to gay men. We have tasks to finish each quarter: how many people visited our site, how many posters did we send out, or how many people tested... but for what? For us or for them? 
Consequently, the so-called "community engagement" in Chinese public health interventions was largely simple rationalized and standardized problem-solving by NGOs to complete tasks from a public health authority (Long, 2018; Miller, 2013; Spires, 2011). Intervention design was still mostly expert-driven by the government with a top-down model lacking substantial community engagement and "local knowledge" (Hyde, 2007; Liu, 2010), which made it unable to effectively "co-produce" (Eyal, 2013; Latour, 2005) education materials that were "gay enough" to bridge the gap between MSM subject and gay identity.

As a result, when those problematic health education materials were distributed, an unintended consequence followed: the hyper-visibility of MSM discourse and representation became a barrier instead of a facilitator for gay men to internalize the MSM subject. Its hegemonic presence fostered discontent and resistance for some gay men, instead of compliant acceptance. When discussing public health's contribution to the visibility of the gay men's community, Xiao-Chen, a 32-yearold experienced Changsha NGO worker quickly disapproved:

No, no, no, no. The only thing they care about is that the HIV infection rates among gay men are high, so their stereotypical image is satisfied. I think this kind of exposure does not help LGBTQ at all in the empowerment issues, or the public understanding of LGBTQ. None! [...] the gay men they know are not the real gay, you know? There are gay men who do not have AIDS.

These criticisms were further confirmed around May $17^{\text {th }}, 2019$, the International Day Against Homophobia, Transphobia, and Biphobia. A series of censorship and repression happened to eliminate the rainbow flag symbol and relevant activities in public, particularly in university campuses in China. Kang-Kang, an NGO worker in Beijing sent me a picture of a pile of public health educational pamphlets in his office and said: "There are so many red ribbons! But red is not the only color of a rainbow."

These dissatisfactions did not only end up as complaints or remorse; gay men and NGOs still tried to create an alternative and contested network for their social life outside of the shadow of the HIV/AIDS agenda. These attempts were highly constrained, yet they may potentially produce social change. For example, although received a warning from the local police department, DanDan and his organization still organized the book club, only without public advertising. They were also considering quitting a government AIDS care project due to the project's mere focus on the 
"MSM side" of gay men and disdained for NGOs' suggestions. "I hope our LGBTQ NGOs can be organized against that project, and maybe other things." Dan-Dan said to me, then paused, "But it is hard. At least we can do something right now. We can do nothing if our organization is gone."

\section{Discussion: Beyond MSM and toward a reflexive public health}

Controversies around MSM are not only about its name and representation. MSM is also a new subject, a "kind of people" that public health assembles to associate people under this classification with HIV/AIDS for public health goals. The creation and expansion of MSM classification is never a natural process. Numbers, images, selected knowledge, and news are mobilized by public health experts to put gay men into the looping network that "extends the range of entities at work in the world and actively participating in transforming some of them into faithful and stable intermediaries" (Latour, 2005, p. 257). Yet this looping network is not an iron cage and gay men are not merely passive recipients of this MSM subject. Instead, many of them identify the problematic assumptions behind the network and resist the naturalization of these associations between themselves and HIV/AIDS through the MSM classification.

By examining gay men's interaction with MSM classification in China, this study also highlights the unique biopolitics and nuanced relations between biopower and authoritarian repressive power in making and sustaining the association. These two kinds of power can contribute to each other and contradict each other at the same time. China's regulation of civil society represses the public expression of many LGBTQ community agendas, such as civil rights and anti-discrimination campaigns, and overemphasizes medicalized MSM knowledge and discourse. As a result, the MSM subject that epitomizes the association between gay men and HIV/AIDS becomes hegemonic in the public sphere, which facilitates the internalization of this subject within gay men through various biopower techniques that public health employs.

However, the repressive state apparatuses and public health institutions could also fail. The authoritarian politics institutionally precludes stakeholder engagements in the expertise network that design the health education material. Without gay men's local knowledge and substantial engagement, the network that tries to translate gay men into MSM fails to bridge the gap between them. Unsuccessful framing happens as an unintended consequence. Gay men may resist this 
subject and urge a more comprehensive public representation of themselves. People's "not gay enough" comments on public health education materials indicate rejections to both public health intervention and the reductionist view of their life experiences. It is ironic to see how "MSM," an invention designed to destigmatize gay men from HIV/AIDS, could in fact strengthen gay men's association with HIV/AIDS, which alerts us the risk of the "high-risk" labels. This finding echoes Hyde (2007) and Liu's (2010) studies on HIV/AIDS campaigns on Chinese ethnic minority communities, which shows how the top-down health intervention model that ignores and excludes local knowledge could transform a destigmatization campaign into a stigmatization process.

Furthermore, this study rethinks the meaning of classification in public health's knowledge productions. The naturalized behavioral classification disguised the fact that classifications of humankind are always "moving targets," which are constantly made and remade (Hacking, 2007). The current ways of classification should never be taken for granted. It is true that epidemiologists find a higher HIV prevalence among MSM as a population. However, more specific historical facts, social contexts, and practical considerations were all contributors to the assembling of this classification (Epstein, 1996; Martucci, 2010), while the use of counting, quantification, and correlations are merely engines of making up people, not the reasons why a specific group is classified in a specific way (Hacking, 1996, 2007). Once a classification is established, it often creates a new reality with its performative power, produces new numbers and loops back to justify and reinforce the classification. In a study of a Shanghai public health clinic, for example, Sun (2016) shows that imbalanced public health interventions and the expansion of HIV-related services toward MSM can produce and reconfirm a higher HIV prevalence number among MSM compared to other "high-risk populations" that received less attention.

After all, what is the essential "high-risk" characteristic of MSM? The behavior of "having sex with men" itself is not a high-risk practice for transmitting HIV. If we take a more careful look at many "risk-behaviors" that are associated with MSM, more problems emerge. For example, "having multiple sexual partners" is considered as one of the reasons why MSM is labeled a "highrisk" population in public health. However, the relationship between merely "having multiple sexual partners" and HIV infection risk is not clearly established in experimental studies (Kalichman and Grebler, 2010; Lurie and Rosenthal, 2010). A more plausible reasoning is that people might have a higher chance of getting HIV infection due to the higher chance of not having 
protections during or before sex with multiple sexual partners. Similar conjectures could be made about other established "high-risk behaviors" such as recreational drug use and sex while inebriated. Yet it was the "men who have sex with men" that became a taken-for-granted high-risk population classification, not the "people who have unprotected sex."

The purpose of this study is neither simply criticizing the assumptions and use of MSM in public health education materials nor public health itself on its own. MSM's power and problems do not lie in the three words but practices around it. We can only understand MSM's consequences by contextualizing the social environment public health knowledge productions and interventions are embedded in. What public health needs are not simply abandoning the use of "MSM," but to be more reflexive in its knowledge production and intervention implementation (Perez-Brumer et al., 2016). In other words, public health should recognize the historical, social, cultural, and political environment that its knowledge production mechanism now occupies. It should also acknowledge its target's multiple aspects of life and needs, which do not necessarily always match public health's goals. More importantly, it needs to understand its performative power and its potential symbolic violence its knowledge production and implementation carries. 


\section{Reference}

Adam, B.D., 2011. Epistemic fault lines in biomedical and social approaches to HIV prevention. J. Int. AIDS Soc. 14, S2.

Australian Federation of AIDS Organizations, 2020. HIV in Australia 2020.

Altman, D., Aggleton, P., Williams, M., Kong, T., Reddy, V., Harrad, D., Reis, T., Parker, R., 2012. Men who have sex with men: stigma and discrimination. The Lancet 380, 439-445.

Asthana, S., Oostvogels, R., 2001. The social construction of male "homosexuality" in India: implications for HIV transmission and prevention. Soc. Sci. Med. 52, 707-721.

Ballester-Arnal, R., Gil-Llario, M.D., Giménez-García, C., Kalichman, S.C., 2015. What Works Well in HIV Prevention Among Spanish Young People? An Analysis of Differential Effectiveness Among Six Intervention Techniques. AIDS Behav. 19, 1157-1169.

Barad, K., 2007. Meeting the Universe Halfway: Quantum Physics and the Entanglement of Matter and Meaning. Duke University Press.

Bastien, S., 2011. Fear appeals in HIV-prevention messages: young people's perceptions in northern Tanzania. Afr. J. AIDS Res. 10, 435-449.

Beyrer, C., Baral, S.D., Van Griensven, F., Goodreau, S.M., Chariyalertsak, S., Wirtz, A.L., Brookmeyer, R., 2012. Global epidemiology of HIV infection in men who have sex with men. The Lancet 380, 367-377.

Boellstorff, T., 2011. But do not identify as gay: A proleptic genealogy of the MSM category. Cult. Anthropol. 26, 287-312.

Boyce, P., 2007. 'Conceiving Kothis': Men Who Have Sex with Men in India and the Cultural Subject of HIV Prevention. Med. Anthropol. 26, 175-203.

Carrillo, H., Hoffman, A., 2016. From MSM to heteroflexibilities: Non-exclusive straight male identities and their implications for HIV prevention and health promotion. Glob. Public Health 11, 923936.

China Centers for Disease Control and Prevention, 2017. 2017 National HIV/AIDS Epidemic Report. Chin. J. AIDS STD 677-677.

Chua, L.J., Hildebrandt, T., 2013. From Health Crisis to Rights Advocacy? HIV/AIDS and Gay Activism in China and Singapore. Volunt. Int. J. Volunt. Nonprofit Organ. 25, 1583-1605.

Epstein, S., 1996. Impure Science: AIDS, Activism, and the Politics of Knowledge, 1st edition. ed. University of California Press, Berkeley, Calif.

Eyal, G., 2013. For a Sociology of Expertise: The Social Origins of the Autism Epidemic. Am. J. Sociol. 118, 863-907. 
Foucault, M., 1990. The History of Sexuality, Vol. 1: An Introduction, Reissue edition. ed. Vintage, New York.

Guta, A., Strike, C., Flicker, S., J. Murray, S., Upshur, R., Myers, T., 2014. Governing through community-based research: Lessons from the Canadian HIV research sector. Soc. Sci. Med. 123, 250-261.

Hacking, I., 2007. Kinds of People: Moving Targets. Proc. Br. Acad. 151, 285-318.

Hacking, I., 2004. Between Michel Foucault and Erving Goffman: between discourse in the abstract and face-to-face interaction. Econ. Soc. 33, 277-302.

Hacking, I., 1996. The Looping Effects of Human Kinds, in: Sperber, D., Premack, D., Premack, A.J. (Eds.), Causal Cognition. Oxford University Press, pp. 351-383.

Huang, Y., 2018. Media Representation of Tongxinglian in China: A Case Study of the People's Daily. J. Homosex. 65, 338-360.

Hyde, S.T., 2007. Eating spring rice: The cultural politics of AIDS in Southwest China. Univ of California Press.

Kalichman, S.C., Grebler, T., 2010. Reducing Numbers of Sex Partners: Do We Really Need Special Interventions for Sexual Concurrency? AIDS Behav. 14, 987-990.

Kong, T.S., 2016. The sexual in Chinese sociology: Homosexuality studies in contemporary China. The Sociol. Rev., 64(3), 495-514.

Lampland, M., 2010. False numbers as formalizing practices. Soc. Stud. Sci. 40, 377-404.

Latour, B., 2005. Reassembling the Social: An Introduction to Actor-Network-Theory. Oxford University Press.

Latour, B., 1987. Science in action: How to follow scientists and engineers through society. Harvard university press.

Lieberthal, K., Oksenberg, M., 1990. Policy Making in China: Leaders, Structures, and Processes. Princeton University Press, Princeton.

Liu, C., Meyers, K., 2019. Beyond clinical trials: social outcomes of structured stakeholder engagement in biomedical HIV prevention trials in China. Cult. Health Sex.

Liu, C., Zhang, Y., Pan, S.W., Cao, B., Ong, J.J., Fu, H., Wu, D., Fu, R., Wei, C., Tucker, J.D., Tang, W., 2020. Anticipated HIV Stigma Among HIV Negative Men Who Have Sex with Men in China: A Cross-Sectional Study. BMC Infect. Dis.

Liu, S., 2010. Passage to Manhood: Youth Migration, Heroin, and AIDS in Southwest China, 1 edition. ed. Stanford University Press, Stanford, Calif.

Long, Y., 2018. The Contradictory Impact of Transnational AIDS Institutions on State Repression in China, 1989-2013. Am. J. Sociol. 124, 309-366. 
Lorway, R., 2017. Making global health knowledge: documents, standards, and evidentiary sovereignty in HIV interventions in South India. Crit. Public Health 27, 177-192.

Lupton, D., 1995. The Imperative of Health: Public Health and the Regulated Body, 1 edition. ed. SAGE Publications Ltd, London; Thousand Oaks, Calif.

Lurie, M.N., Rosenthal, S., 2010. Concurrent Partnerships as a Driver of the HIV Epidemic in SubSaharan Africa? The Evidence is Limited. AIDS Behav. 14, 17-24.

Mantell, J.E., Schinke, S.P., Akabas, S.H., 1988. Women and AIDS prevention. J. Prim. Prev. 9, 18-40.

Martucci, J., 2010. Negotiating Exclusion: MSM, Identity, and Blood Policy in the Age of AIDS. Soc. Stud. Sci. 40, 215-241.

Miller, C.J., 2016. Dying for money: The effects of global health initiatives on NGOs working with gay men and HIV/AIDS in northwest China. Med. Anthropol. Q., 30(3), 414-430.

Muòoz-Laboy, M.A., 2004. Beyond 'MSM': Sexual Desire among Bisexually-Active Latino Men in New York City. Sexualities 7, 55-80.

National Bureau of Statistics of China, 2017. China Statistical Yearbook 2017. National Bureau of Statistics of China, Beijing.

Perez-Brumer, A.G., Oldenburg, C.E., Reisner, S.L., Clark, J.L., Parker, R.G., 2016. Toward 'reflexive epidemiology': Conflation of cisgender male and transgender women sex workers and implications for global understandings of HIV prevalence. Glob. Public Health 11, 849-865.

Rofel, L., 2007. Desiring China: Experiments in neoliberalism, sexuality, and public culture. Duke University Press.

Spires, A.J., 2011. Contingent Symbiosis and Civil Society in an Authoritarian State: Understanding the Survival of China's Grassroots NGOs. Am. J. Sociol. 117, 1-45.

Sun, Z., 2016. Manufacturing Consent: Research on the Link of Stigma between AIDS and Gay Men which Constructed by the Public Health (Master). East China Normal University, Shanghai.

Timmermans, S., Tavory, I., 2012. Theory Construction in Qualitative Research: From Grounded Theory to Abductive Analysis. Sociol. Theory 30, 167-186.

Truong, N., Perez-Brumer, A., Burton, M., Gipson, J., Hickson, D., 2016. What is in a label? Multiple meanings of 'MSM' among same-gender-loving Black men in Mississippi. Glob. Public Health $11,937-952$.

United States Centers for Disease Control and Prevention, 2017. HIV in the United States: at a glance. 2015.

Waidzunas, T., 2012. Young, Gay, and Suicidal: Dynamic Nominalism and the Process of Defining a Social Problem with Statistics. Sci. Technol. Hum. Values 37, 199-225.

Wong, A.D., 2005. The reappropriation of tongzhi. Language in society, 34(5),763-793. 
Young, R.M., Meyer, I.H., 2005. The Trouble With "MSM" and "WSW": Erasure of the Sexual-Minority Person in Public Health Discourse. Am. J. Public Health 95, 1144-1149.

Zhang, Y., 2017. Scare Tactic and its Damage: Take AIDS Publication and Education as an Example (Ai zi bing xuan chuan jiao yu zhong de kong he ce lue ji qi wei hai). Thinking (Si xiang zhan xian) $43,18-24$. 